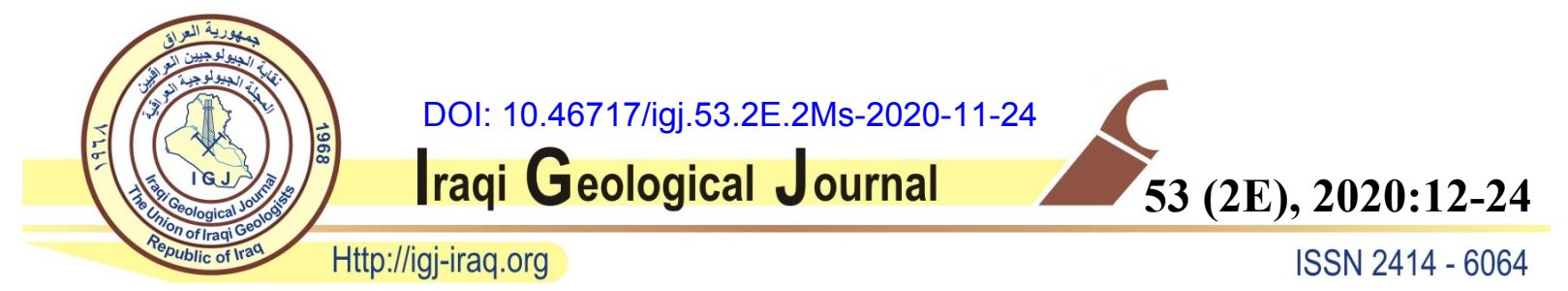

\title{
GROUNDWATER VULNERABILITY ASSESSMENT USING DRASTIC MODEL OF UP AL-KHASSA DAM SUB-BASIN, KIRKUK, NE IRAQ
}

\author{
${ }^{1}$ Madyan Raad Ghazal Al-Gburi* and ${ }^{1}$ Omer S. Ibrahiem Al-Tamimi \\ ${ }^{1}$ Department of Applied Geology, College of Science, University of Kirkuk, Iraq \\ ${ }^{*}$ E-mail: midian680@yahoo.com \\ Received: 21 August 2020; accepted: 12 October 2020
}

\begin{abstract}
Several studies and assessments have been conducted of areas exposed to pollution, especially areas that contain aquifer. The final extraction of the vulnerability map of the groundwater was constructed through the use of the DRASTIC method by applying the linear equation of the seven coefficients in the Arc GIS software program (Version 10.4). The aim of the study to assess aquifer vulnerability to pollution. Results, vulnerability map range between 75-126 (very low, low, and medium), the study area consists of very low and low vulnerability, except some areas medium vulnerability close to the center of the subbasin in the standard vulnerability map (s) and 91-149 (very low, low, and medium) for the agriculture or pesticide vulnerability map (p), the medium vulnerability occupies a greater area the center of the sub-basin.
\end{abstract}

Keywords: Vulnerability; DRASTIC; Groundwater; GIS; Al-Khassa dam

\section{INTRODUCTION}

Serval studies and assessments have been conducted of areas exposed to pollution, especially areas that contain aquifer. Where the increase in the use of groundwater to include some laws to protect the groundwater from pollutants and also the use of fertilizers and pesticides that infiltrate into the ground up to the reservoir in addition to industrial waste and ...etc, all of these activities increase the possibility that makes the groundwater polluted (Aller et al., 1987). Some man-made pollutants affect groundwater: placing liquids and products that are soluble on the earth's magic, placing some pollutants or burying them under the ground above the water level and burying pollutants or from the way to inject it below the groundwater level (Lehr et al., 1976). Therefore, it became necessary to produce vulnerability maps to the aquifer. The first interest in the dangers that affect the groundwater is done by Margat (1968), then the development in this field increased, especially through the development of assessment maps showing the aquifer (Aller, 1985), (Van Stempvoort et al., 1993), (Foster., 1987) and (Aller et al., 1987). The DRASTIC method has been especially applied to protect 


\section{Iraqi Geological Journal Al-Gburi and Al-Tamimi 53 (2E), 2020: 12-24}

aquifer from exposure to pollutants. These studies are especially important from an environmental point of view to avoid environmental hazards or environmental degradation (Mendoza and Barmen, 2006). Also, these studies provide information on how to use land and manage water resources, especially by protecting groundwater from any pollutants (Bachmat and Collin, 1990). Further studies and assessments are being carried out on aquifer exposure in most of the countries with an interest in this field, particularly in areas where groundwater is exposed to pollutants as a result of increased population growth, industrial development and the use of agricultural land for certain fertilizers which in turn affect groundwater. The interest in assessing the ability to influence the identification of areas that could be more contaminated than others due to their proximity to the land surface or some human activity, where once knowledge of the defect can determine proper planning land use and avoiding groundwater contamination (Babiker et al., 2005). It is necessary to know the natural and geological conditions that affect groundwater. The aim of the study is to assess aquifer vulnerability for pollution in the study area.

\section{STUDY AREA}

The study area is in the northeast Kirkuk Governorate, it is located between coordinates (3952964-3928476 East) and (451807-483362 North), it occupies $420 \mathrm{~km}^{2}$, approximately the study area is far from the city centre of Kirkuk $(21) \mathrm{km}$, the dam site the west of the subbasin, which is the same direction as the general drainage of the area. The area includes about 26 villages and the elevations of the study area range from 441-906 $\mathrm{m}$ above sea level (Fig. 1). The area is one of the upper parts Al-Adhim river basin and one of the main seasonal tributaries that originate in the Iraqi lands.

The sub-basin consists of several geological formations ranging in age from the upper Miocene (Tertiary period) to the middle Holocene (Quaternary period) which are the Injana, Mukdadiyah, and Bai-Hassan formations and also include the Quaternary deposits (Sissakian, 1992). Injana Formation site in the far eastern part, which covers about $0.94 \mathrm{~km}^{2}$, while the Mukdadiyah Formation is in the eastern and northeastern parts, it covers approximately 30.59 $\mathrm{km}^{2}$, while the Bai-Hassan Formation occupies $354.74 \mathrm{~km}^{2}$ of the sub-basin, addition to that the presence of the Quaternary deposits as Quaternary slope deposits and Quaternary Polygenetic deposits covering some parts western and eastern $\left(33.73 \mathrm{~km}^{2}\right)$ from the study area, the border from the north and east side which represent recharge area by the north anticline (Fig. 2). Depending on the tectonic and structural conditions, the area located in the unstable shelf in the area of low folded zone in the Chamchamal sub-zone of Chamchamal-Batam within the foothill zone (Buday and Jassim, 1987). 


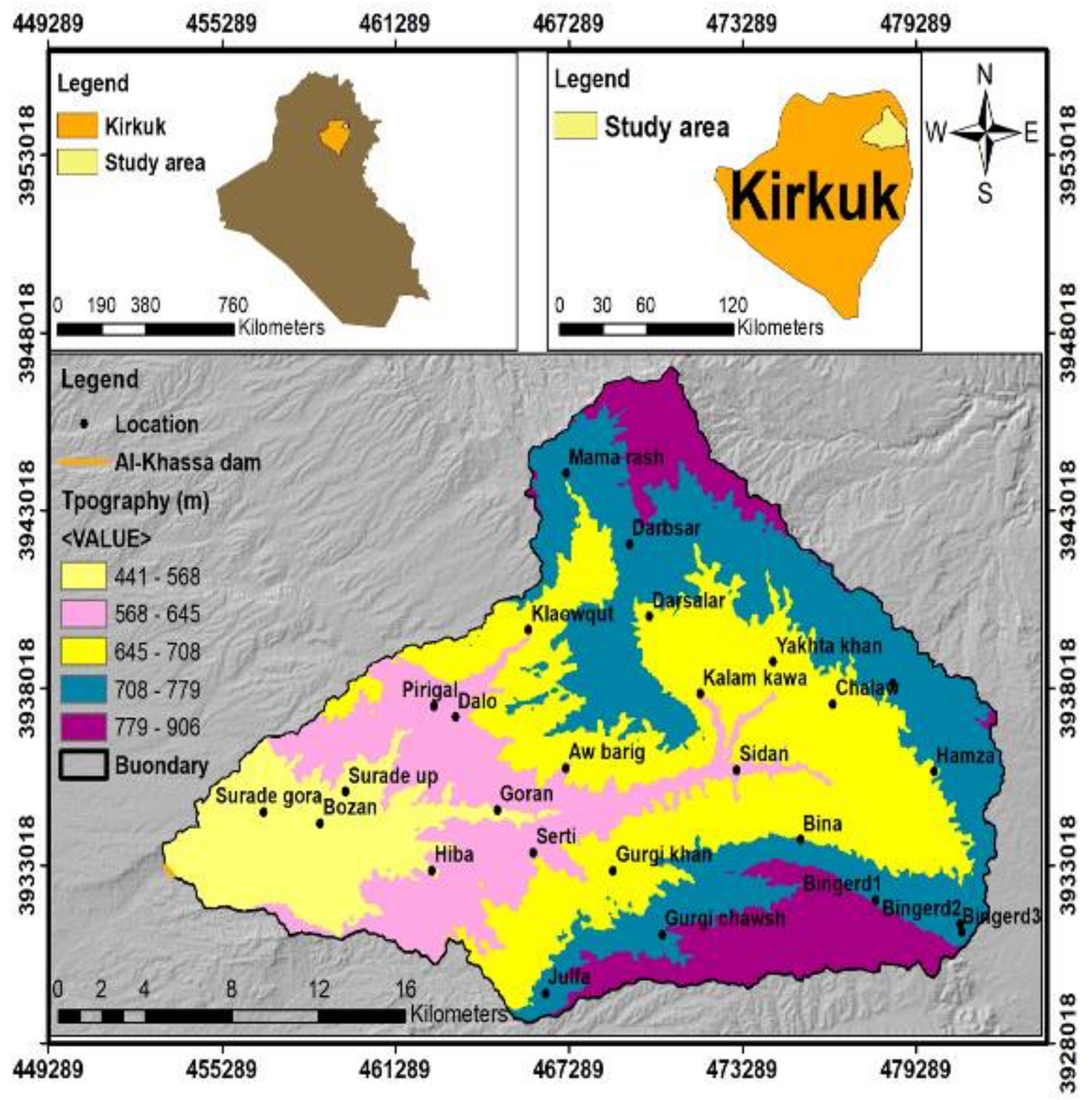

Fig. 1. Location map of the study area

\section{MATERIALS AND METHODS}

DRASTIC method depends on 7 basic factors: Depth of groundwater (D), net recharge (R), aquifer media (A), soil media (S), topography (T), impact of the vadose (I), and hydraulic conductivity $(\mathrm{C})$. Basic data of the method were obtained through fieldwork, scientific references, and the Water Resources Department of Kirkuk, as follows, groundwater depths in the study area were obtained by measuring the depths of 26 wells. Net recharge was obtained after calculating the rate of feeding (Ali, 2020). 


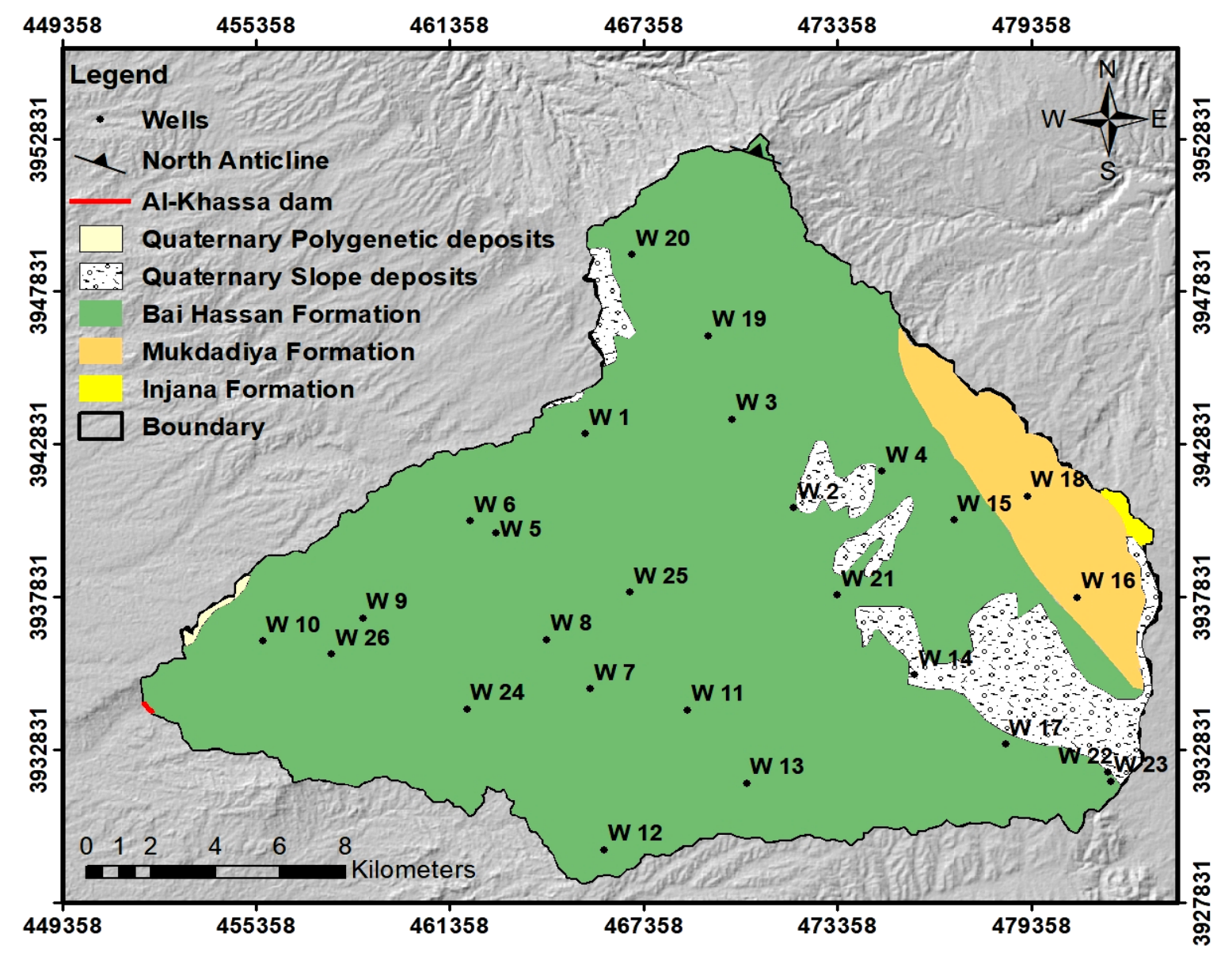

Fig. 2. Geological map of the study area modified after (Sissakian, 1992)

The aquifer media from saturation thicknesses for borehole and the impact of the vadose zone from the unsaturated zone for borehole were calculated in the current study depending on wells lithological (Iraq Ministry of Water Resources, Department of Kirkuk). The special data for the soil in the study area obtained from the soil database (Harmonized world soil database) (Nachtergaele et al., 2008). The topography of the region data was extracted from the Digital Elevation Model (DEM). Concerning hydraulic conductivity, the values were obtained by performing a pumping test of eight wells (pumping with observation wells) in the area. The description of each parameter was given depending on the data values in (Tables 1 and 2) (Aller et al., 1987). Through the use of the spatial analysis tools in the ArcGIS Software (10.4). Then the seven parameters that were formed in the form of a map for each parameter was added and multiplied by the special weight of each parameter by the linear equation 1 (Aller, 1985). Using the map algebra tool in the Arc GIS Software (V. 10.4). The result is to create a vulnerability map based on the Table 3 (Aller, 1985) (Fig. 3).

$\mathrm{Dr} \mathrm{Dw}+\mathrm{Rr} \mathrm{Rw}+\mathrm{Ar} \mathrm{Aw}+\mathrm{Sr} \mathrm{Sw}+\mathrm{Tr} \mathrm{Tw}+\mathrm{Ir} \mathrm{Iw}+\mathrm{Cr} \mathrm{Cw}=$ Vulnerability map where: $r=$ rating. $\mathrm{W}=$ weight. 
Table 1. Weight of the factors in the DRASTIC method (Aller et al., 1987)

\begin{tabular}{|l|c|c|}
\hline \multirow{2}{*}{ Parameters } & \multicolumn{2}{|c|}{ Drastic weight } \\
\cline { 2 - 3 } & Standard & Pesticides \\
\hline Depth for groundwater (D) & 5 & 5 \\
\hline Net Recharge (R) & 4 & 4 \\
\hline Aquifer media (A) & 3 & 3 \\
\hline Soil media (S) & 2 & 5 \\
\hline Topography (T) & 1 & 3 \\
\hline Impact of vadose zone (I) & 5 & 4 \\
\hline Hydraulic conductivity (C) & 3 & 2 \\
\hline
\end{tabular}

\section{RESULTS AND DISCUSSION}

\section{Depth of Groundwater (D)}

The depth of groundwater is one of the main factors in terms of the weight within the DRASTIC method. A close correlation is associated with the time the pollutant reaches the liquid phase to cross and reach the groundwater table. This indicates when the groundwater level in a degree of depth large that delays the arrival of pollutants in the liquid phase to the groundwater level, in this case, the pollutants in the ground are diluted, whether by analysis or by natural reactions (Hamamin, 2011). The depths of groundwater in the area range between 5-82 m, the max depth of groundwater at the well 13, and the min depth of the groundwater at the well 18. Necessary know the area elevations in an accurate form, as the study area is represented by several heights and depressions, which causes a difference in the depth of groundwater between one well and another. The map was prepared by the internal of the reverse weight (IDW) of the spatial analysis within the Arc GIS Software (V. 10.4). IDW gives us an idea of the non-measured locations and the values in which the measurement was made. Depending on Table 2, as the depths that fall within the number 1 are less susceptible to be polluted than values that fall within the number 10 that are susceptible to be polluted, groundwater depth values showed that the rating from 1-7 (Fig. 4A).

\section{Net Recharge (R)}

The primary groundwater source is the rain that infiltrates into the soil. Net recharge refers to the amount of rainwater that infiltrates into the ground per unit area until it reaches the groundwater, which in turn transports pollutants vertically to the groundwater level and horizontally within the aquifer while do not forget the role of an unrestricted aquifer net recharge is high, meaning that it is easy to enter pollutants or reach the groundwater or aquifer and the exact opposite is true (Aller, 1985). 
Table 2. Ranges and rating for parameters (Aller et al., 1987)

\begin{tabular}{|c|c|c|c|}
\hline Parameter & Range & Rating & $\begin{array}{c}\text { Typical } \\
\text { rating }\end{array}$ \\
\hline \multirow{7}{*}{$\begin{array}{l}\text { Depth for } \\
\text { groundwater (D) } \\
\text { (m) }\end{array}$} & 0 and 1.5 & 10 & - \\
\hline & $1.5-4.5$ & 9 & - \\
\hline & $4.5-9$ & 7 & - \\
\hline & $9-15$ & 5 & - \\
\hline & $15-23$ & 3 & - \\
\hline & $23-30$ & 2 & - \\
\hline & More than 30 & 1 & - \\
\hline \multirow{5}{*}{$\begin{array}{l}\text { Net Recharge (R) } \\
(\mathrm{mm} / \mathrm{y})\end{array}$} & Less than 50.8 & 1 & - \\
\hline & $50.8-101.6$ & 3 & - \\
\hline & $101.6-177.8$ & 6 & - \\
\hline & $177.8-254$ & 5 & - \\
\hline & More than 254 & 9 & - \\
\hline \multirow{9}{*}{ Aquifer media (A) } & Massive Shale & $1-3$ & 2 \\
\hline & Metamorphic/Igneous & 25 & 3 \\
\hline & Weathered. Metamorphic/Igneous Thin Bedded Sandston, & $3-5$ & 4 \\
\hline & Limestone, Shale Sequences & $5-9$ & 6 \\
\hline & Massive Sandstone & $4-9$ & 6 \\
\hline & Massive Limestone & $4-9$ & 6 \\
\hline & Sand and Gravel & $6-9$ & 8 \\
\hline & Basalt & $2-10$ & 9 \\
\hline & Karst Limestone & $9-10$ & 10 \\
\hline \multirow{9}{*}{ Soil media (S) } & Thin or Absent & 10 & - \\
\hline & Gravel & 10 & - \\
\hline & Sand & 9 & - \\
\hline & Shrinking and/or Aggregated Clay & 7 & - \\
\hline & Sandy Loam & 6 & - \\
\hline & Loam & 5 & - \\
\hline & Silty Loam & 4 & - \\
\hline & Clay Loam & 3 & - \\
\hline & Nonshrinking and Nonaggregated Clay & 1 & - \\
\hline \multirow{5}{*}{$\begin{array}{l}\text { Topography (T) } \\
\text { (Percent slop) }\end{array}$} & $0-2$ & 10 & - \\
\hline & $2-6$ & 9 & - \\
\hline & $6-12$ & 5 & - \\
\hline & $12-18$ & 3 & - \\
\hline & More than 18 & 1 & - \\
\hline \multirow{10}{*}{$\begin{array}{l}\text { Impact of vadose } \\
\text { zone (I) }\end{array}$} & Silt/Clay & $1-2$ & 1 \\
\hline & Shale & $2-5$ & 3 \\
\hline & Limestone & $2-7$ & 6 \\
\hline & Sandstone & $4-8$ & 6 \\
\hline & Bedded Limestone, Sandstone, Shale & $4-8$ & 6 \\
\hline & Sand and Gravel with significant Silt and Clay & $4-8$ & 6 \\
\hline & Metamorphic/Igneous & $2-8$ & 4 \\
\hline & Sand and Gravel & $6-9$ & 8 \\
\hline & Basalt & $2-10$ & 9 \\
\hline & Karst Limestone & $8-10$ & 10 \\
\hline \multirow{6}{*}{$\begin{array}{c}\text { Hydraulic } \\
\text { conductivity }(\mathrm{C}) \\
(\mathrm{m} / \mathrm{d})\end{array}$} & Less than 4 & 1 & - \\
\hline & 4-12 & 2 & - \\
\hline & $12-30$ & 4 & - \\
\hline & $30-40$ & 6 & - \\
\hline & $40-80$ & 8 & - \\
\hline & More than 80 & 10 & - \\
\hline
\end{tabular}




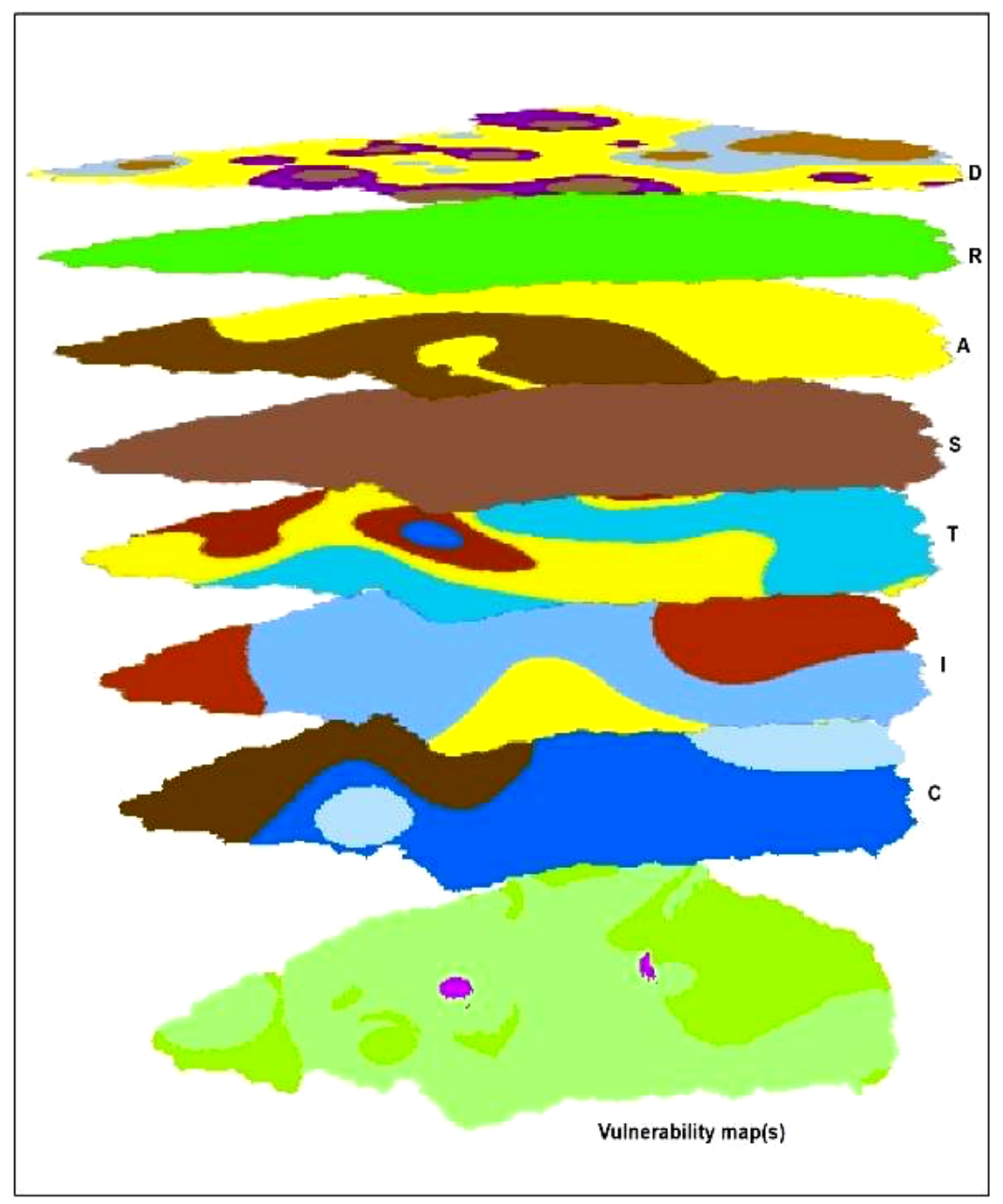

Fig. 3. Methodology of DRASTIC method of the study area

Net recharge represents the total recharge in millimeters of water entering aquifer annually (Mohammadi et al., 2009). This evidence that net recharge pollutants enter by filtering them into the ground layers up to the groundwater, where this factor is considered one of the main factors in in terms of the weight assessing affect the groundwater or aquifer. The polluted groundwater increases with the increase in net recharge from the path of infiltration into groundwater. The average of net recharge is $51.98(\mathrm{~mm} / \mathrm{y})$ according to the chloride mass balance method (CMB) $53.84 \mathrm{~mm} / \mathrm{y}$ and (WTF) method $50.13 \mathrm{~mm} / \mathrm{y}$ in the area (Ali, 2020). The value of net recharge of the contamination potential is low according to Table 2 and Fig. 4B.

\section{Aquifer Media (A)}

The Aquifer media is represented by several elements, whether they are media components of consolidated or unconsolidated elements (sand, limestone, clay, and gravel). In general, the aquifer is the one that gives water in proportion to the need for use and who stores the groundwater in the pores of rocks and also stores water in rock openings, the higher the path length, the fewer pollutants affect the aquifer through dispersion, absorption, or natural 


\section{Iraqi Geological Journal Al-Gburi and Al-Tamimi 53 (2E), 2020: 12-24}

reactions under the ground. Also, the more granular size increases with the presence of some fractions, the greater the of pollutants to reach the aquifer, as the aquifer media are calculated from the saturated thicknesses, the value 2 is less susceptible to be polluted while 10 is most susceptible to be polluted (Table 2) and (Fig. 4C).

\section{Soil Media (S)}

Soil media is defined as the upper layer of the vadose zone. The soil it has a high biological activity, which has a great impact on pollution, especially in the matter of nutrition, where through the soil it is infiltrated into the ground, through infiltration, pollutants are transported perpendicularly to the unsaturated area where whenever the soil in leads to a delay in the transport of pollutants or through absorption and biological reactions, do not forget also the impact of pesticides on agricultural land, as well as the effect of clay, where the greater the amount the slurry, the less the possibility of contamination (Aller, 1985). The area contains soil from type loam. Soil data were obtained according to information obtained from the soil database (Harmonized world soil database) (Nachtergaele et al., 2008) (Table 2) and (Fig. 4D).

\section{Topography (T)}

The topography is characterized by the slope of the land surface and the shift in the slope, when the land surface is a tiny slope i.e. semi-level, the surface water is almost stagnant in its place, meaning, in this case, an increase in the penetration of surface water and some pollutants into the ground, while in the case of the land surface includes medium to high degrees of slopes, pollutants penetration are on the land surface are very little penetration because the precipitation is directly proportional to the slope, fertilizers, pesticides used in agriculture areas lead to an increase in the possibility of contamination of groundwater in the case of the low surface slope, this causes pollutants to accumulate gradually over time (Aller, 1985). The classification in Table 2) was adopted if it was less than 10 in the direction of 1 , i.e. an increase in the probability of pollution, or greater than 1 i.e. is less susceptible to be pollution in the direction of 10 (Fig. 4E).

\section{Impact of the Vadose (I)}

All studies confirm that the soil consisting of gravel and coarse sand is penetrated by pollutants and reaches faster to the aquifer than the soil that includes clay (Weber and Weed, 1974), (Helling and Gish, 1985). In general, the vadose zone represents low water content (unsaturated zone) is defined as the water level or the saturated area intermittently between soil layers and water (Kabera and Zhaohui, 2008). The effect of the vadose zone is not only limited to the saturated area while also includes the unsaturated zone and the saturated zone that are above the aquifer affected the groundwater if the unsaturated region contains fractures 
(Wilson, 1980). These fractures lead to the speed of entry of pollutants, as well as the length of the path affects the groundwater, as the path length increases, the effect of pollutants on the groundwater decreases (Aller, 1985). Precipitation and other types of water precipitate into the unsaturated zone, hence the nature of the substances in the unsaturated zone have a fundamental role in reducing pollutants (Hernandez et al., 2004). The study area includes several elements in the unsaturated area (sand, clay, gravel and sand gravel), since the area includes aquifer of the confined type and semi-confined within the Mukdadiyah and BaiHassan formations, all of these are included sensitive calculations in evaluating the possibility of contamination of groundwater. This effect was evaluated based on the world classification in Table 2, each parameter is described with a degree of contamination probability, the value 1 is less likely to pollute while 10 is more likely to be contaminated (Fig. 4F).

\section{Hydraulic Conductivity (C)}

Hydraulic conductivity is defined as the ability of aquifer materials to transfer water. This flow has an impact on the rate of pollutants moving into groundwater where the hydraulic conductivity is controlled through the interconnection between the granules Closing voids in the aquifer, the origin of these voids is from the porosity that exists between the grains or some fractures that have a role in increasing the transport of pollutants (Aller, 1985). Hydraulic conductivity is very important, it controls the rate of groundwater flow in the aquifer, this effect leads to controlling the rate of movement of pollutants (Baalousha, 2006). In the area, the pumping test was conducted in eight wells through eight pumping wells and eight observing wells in Al-Mukdadiyah and Bai-Hassan formations, where the values of hydraulic conductivity are $6.1-46.18 \mathrm{~m} / \mathrm{d}$. Value of 1 is less likely to be contaminated, while a value of 10 is more likely to be contaminated (Table 2) and (Fig. 5A).

\section{Vulnerability Map in Study Area}

According to DRASTIC vulnerability Index (DVI) (Table 3) (Aller,1985), that appeared after applying the equation 1 between 75-126 for standard vulnerability map (s), which was classified into three classes (very low, low and medium), showing the moderate value in centre of sub-basin, that occupies $2.53 \mathrm{~km}^{2}(0.6 \%)$, other wells fall within the range of very low and low vulnerability, the very low vulnerability zone represent $132.47 \mathrm{~km}^{2}$ approximately $31.4655 \%$, low vulnerability zone $285 \mathrm{~km}^{2}$ (67.85\%) (Fig. 5B). While agriculture or pesticides vulnerability map (p) ranges from 91-149 through the agriculture or pesticide vulnerability map, the study area is divided into three zone (very low, low, and medium), showing that the parts west, east, north, and center of the sub-basin, it falls within the medium vulnerability, that occupies $124.927 \mathrm{~km}^{2}(29.673 \%)$ while the rest of the sub- 
basin within the range of low vulnerability, that occupies $285.9 \mathrm{~km}^{2}(68 \%)$ the part exception in east of sub- basin, it is within the very low vulnerability, very low vulnerability zone that occupies $9.173 \mathrm{~km}^{2}(2.178 \%)$ from the area (Fig. 5C).

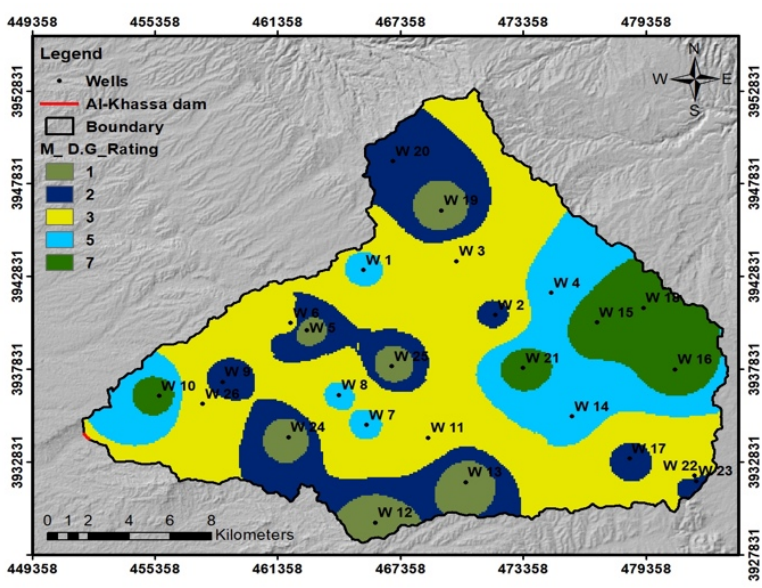

A

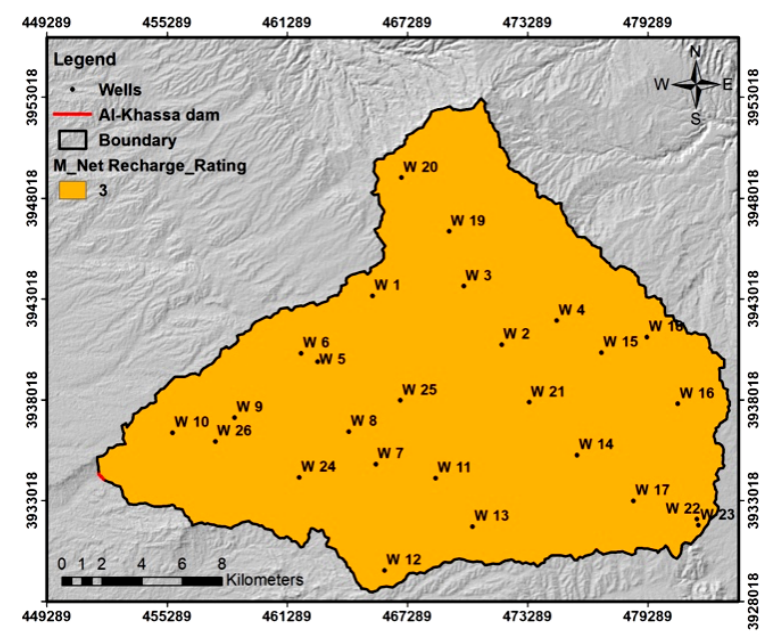

B

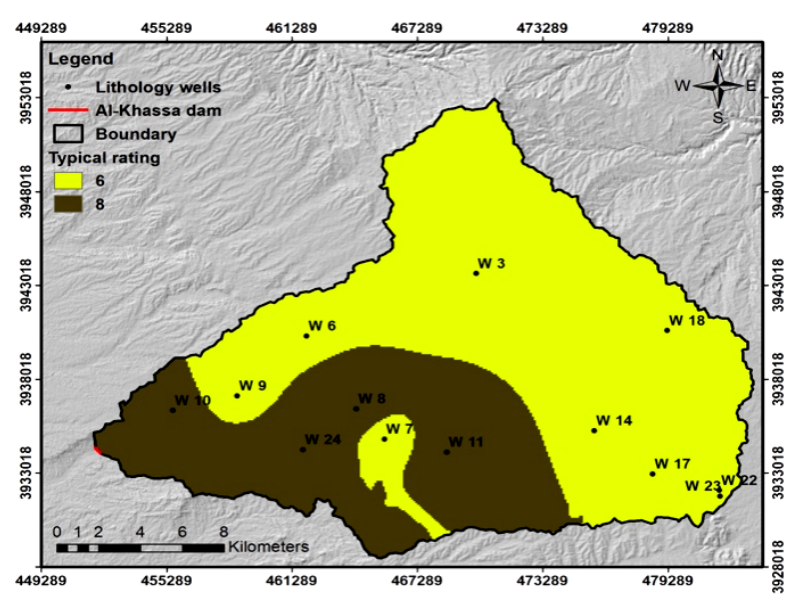

C

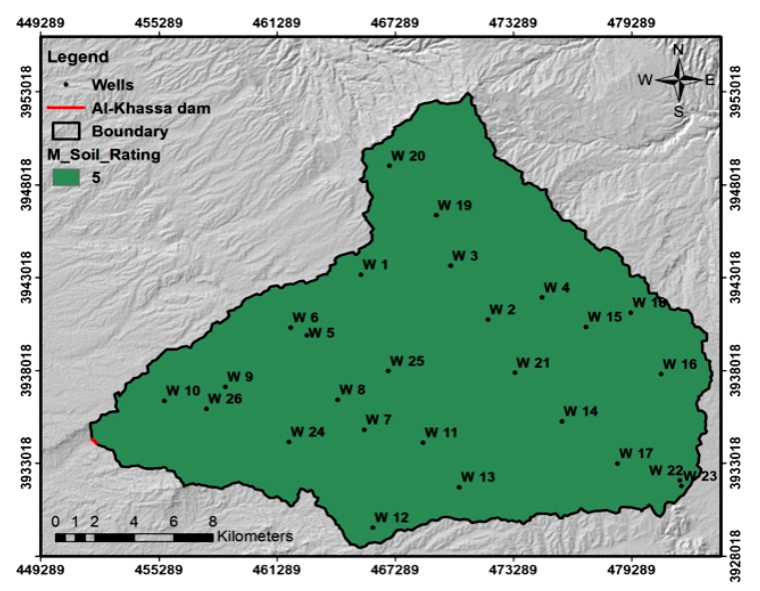

D

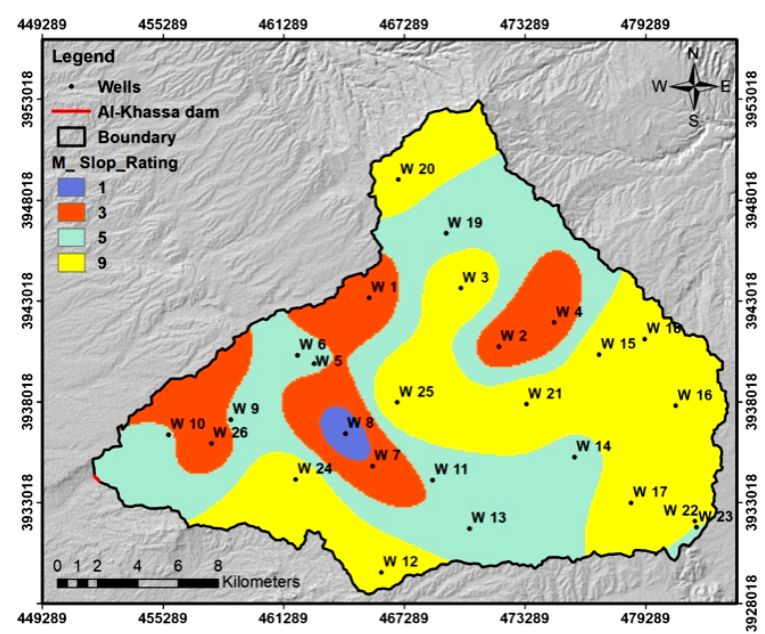

$\mathbf{E}$

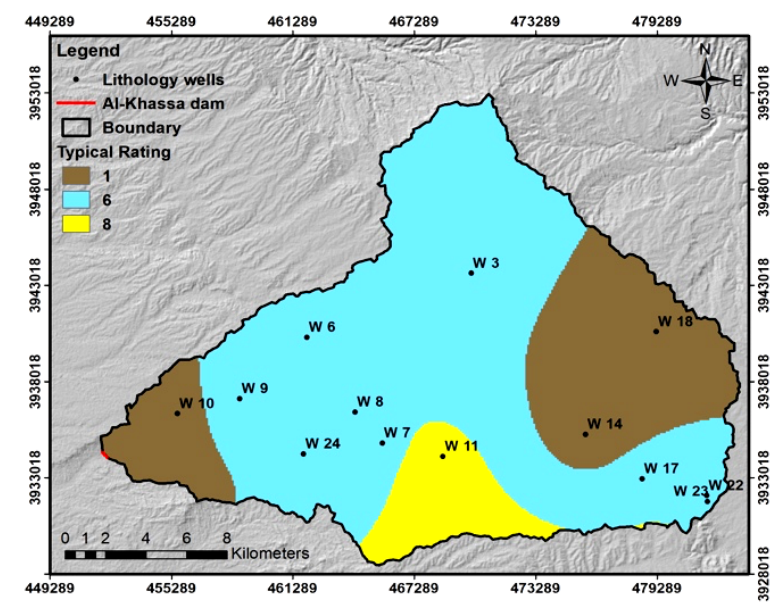

F

Fig. 4. A, B, C, D, E, and F represent depth of groundwater, net recharge, aquifer media, soil, slope, and impact of the vadose, respectively rating of the study area 
Table 3. Ranges of vulnerability using Drastic method (Aller, 1985)

\begin{tabular}{|l|c|}
\hline Drastic vulnerability Index & Vulnerability degree \\
\hline Less than 100 & Very low \\
\hline $100-125$ & Low \\
\hline $125-150$ & Medium \\
\hline $150-200$ & High \\
\hline More than 200 & Very high \\
\hline
\end{tabular}

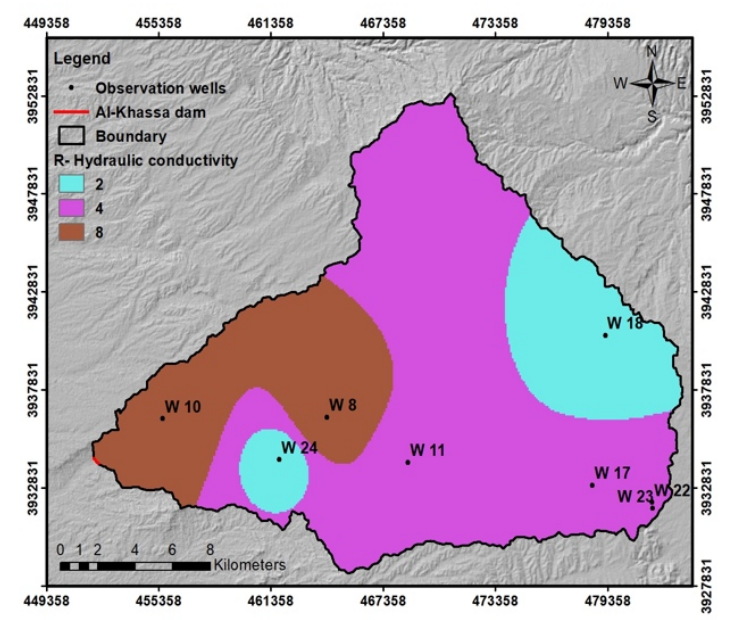

A

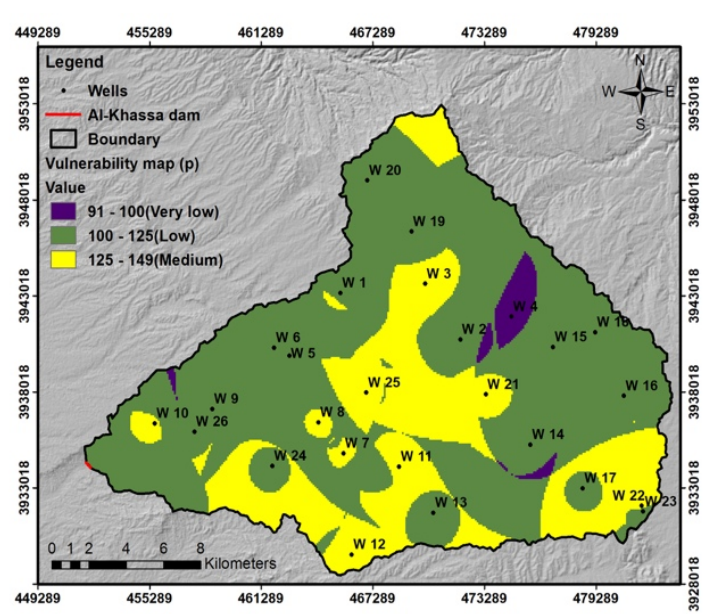

B

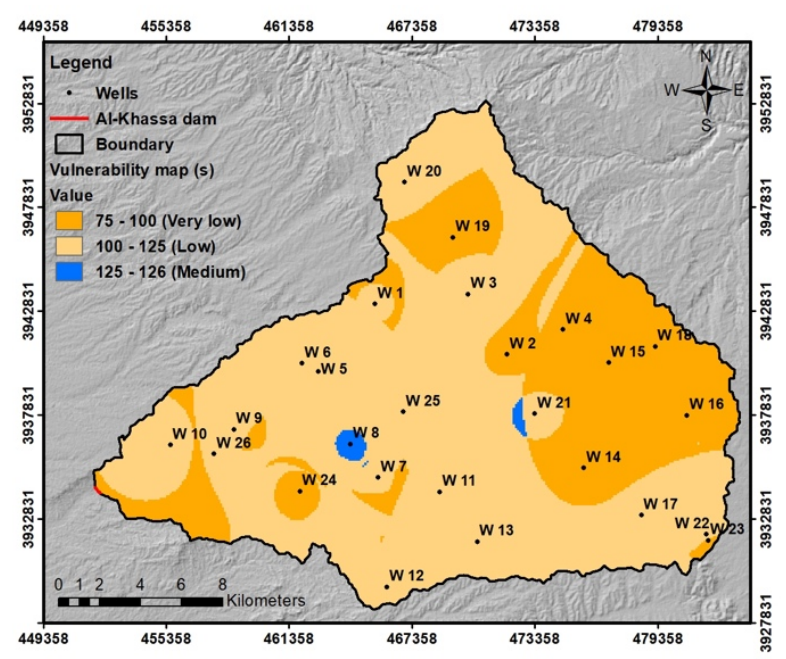

C

Fig. 5. A, B, and C represent hydraulic conductivity rating, standard vulnerability map, and agriculture or pesticide vulnerability map respectively of the study area

\section{CONCLUSIONS}

Through the use of the optimal method in knowing the natural conditions that affect the pollution of the aquifer in the area, which is the DRASTIC method where the required data has been deal with within the DRASTIC method through the use of spatial analysis tools in the Arc GIS Software (V. 10.4). The values range from 75-126, which is between very low 
and medium. Very low vulnerability, especially in the eastern part and some of the western part of the area, while the low vulnerability is in the direction of the western part, which represents the largest percentage of the area except for the centre of sub-basin medium vulnerability in standard vulnerability map (s). In agricultural or pesticides vulnerability map (p) values range from 91-149, vulnerability according to the method index is represented by a very low vulnerability at the zone in the eastern part, while the rest of the zones is represented by the low-medium vulnerability, where the eastern and western parts represent a low vulnerability while not full coverage, and an increase in the medium vulnerability towards the center of the area, western, some of the northern, and eastern parts, which are more in terms of population distribution in the area. Based on the results of the vulnerability map (s), most of the basin are valid to use for human activity commercial and industrial except the small zones in the center of sub-basin. Most of the area is valid for agricultural activities except some parts in the west and east of the sub-basin, where a plan must be put to save the groundwater from possible pollution before using this area in the case of taking into account the agricultural vulnerability map (p). The effect is greater in the Bia-Hassan Formation because of the lithology nature of the formation than what is found in the formation of Mukdadiyah with the least effect. This indicates that the value of high hydraulic conductivity, impact vadose, and topography have a significant impact on the area, especially within the Bia-Hassan Formation.

\section{RECOMMENDATIONS}

Conducting more pumping tests, especially in the northern parts of the area, in addition to analysis for $\mathrm{NO}_{3}$ in the study area. application of the model or the DRASTIC method in all Iraqi governorates concerned groundwater pollution.

\section{ACKNOWLEDGMENTS}

The authors thank Dr. Assistant Professor, Dara Faeq Hamamin, a faculty member at the university of Sulaymaniyah for the efforts and advice, he provided in reviewing the research. The authors are very grateful to the Editor in Chief Prof. Dr. Salih M. Awadh, the Secretary of Journal Mr. Samir R. Hijab and the Technical Editor Dr. Heba S. Al-Mimar for their great efforts and valuable comments.

\section{REFERENCES}

Ali, S. M. 2020. Hydrogeological study and Mathematical Model of the Aquifer Up Al-Khassa Sub-basin Kirkuk, NE Iraq. Unpublished Master Thesis, College of Science, University of Kirkuk, 90.

Aller, L. 1985. DRASTIC: a standardized system for evaluating ground water pollution potential using hydrogeologic settings. Robert S. Kerr Environmental Research Laboratory, Office of Research and Development, US Environmental Protection Agency. 


\section{Iraqi Geological Journal Al-Gburi and Al-Tamimi 53 (2E), 2020: 12-24}

Aller, L., Bennett, T., Lehr, J. H., \& Petty, R. G. Hackett, 1987. DRASTIC: a standardized system for evaluating ground water pollution potential using hydrogeologic settings. USEPA. Cincinnati. OH. USEPA 622p.

Baalousha, H. 2006. Vulnerability assessment for the Gaza Strip, Palestine using DRASTIC. Environmental Geology, 50(3): 405-414.

Babiker, I. S., Mohamed, M. A., Hiyama, T., and Kato, K. 2005. A GIS-based DRASTIC model for assessing aquifer vulnerability in Kakamigahara Heights, Gifu Prefecture, central Japan. Science of the Total Environment, 345(1-3):127-140.

Bachmat, Y., and Collin, M. 1990. Management-oriented assessment of groundwater vulnerability to pollution. Israel Hydrological Service Report, Jerusalem, 6(9): 30.

Buday, T., and Jassim, S. Z. 1987. The Regional geology of Iraq, vol. 2: Tectonism, Magmatism and Metamorphism. Publication of GEOSURV, Baghdad, 352.

Foster, S. S. D. 1987. Fundamental Concepts in Aquifer Vulnerability, Pollution Risk and Protection Strategy.

Hamamin, D. F. 2011. Hydrogeological assessment and groundwater vulnerability map of Basara Basin, Sulaimani Governorate, Iraq, Kurdistan Region. Unpublished PhD thesis, College of Science, University of Sulaimani, $174 \mathrm{P}$.

Helling, C. S., and Gish, T. J. 1985. Soil characteristics affecting pesticide movement into groundwater. 89 (2).

Hernandez, L. R., Bravo, J. A., and Mejuo, M. F. 2004. Map of vulnerability to groundwater contamination. Excelentisima Diputacion Provincial de Alicante, Espana, 174 (A):1029-2004.

Kabera, T., and Zhaohui, L. 2008. A GIS based DRASTIC model for assessing groundwater in shallow aquifer in Yuncheng Basin, Shanxi, China. Research Journal of Applied Sciences, 3(3):195-205.

Lehr, J. H., Wayne, A. Pettyjohn, T. W., Bennett, J. R., and Sturtz, L. E., 1976. A manual of laws, regulations, and institutions for control of ground water pollution; U.S.EPA-440, 9-76-006.

Margat, J. 1968. Vulnerability of Groundwater to Pollution. Orleans, France, 6-7.

Mendoza, J. A., and Barmen, G., 2006. Assessment of groundwater vulnerability in the Río Artiguas basin, Nicaragua. Environmental Geology, 50(4): 569-580.

Mohammadi, K., Niknam, R., and Majd, V. J. 2009. Aquifer vulnerability assessment using GIS and fuzzy system: a case study in Tehran-Karaj aquifer, Iran. Environmental geology, 58(2): 437-446.

Nachtergaele, F. O., van Velthuizen, H., Verelst, L., Batjes, N. H., Dijkshoorn, J. A., van Engelen, V. W. P., and Prieler, S. 2008. Harmonized world soil database (version 1.0).

Sissakian, V. K. 1992. The Geology of Kirkuk Quadrangle Sheet NI-38-2, Scale 1: 250000. GEOSURV, Baghdad.

Stempvoort, D. V., Ewert, L., and Wassenaar, L. 1993. Aquifer vulnerability index: a GIS-compatible method for groundwater vulnerability mapping. Canadian Water Resources Journal, 18(1): 25-37.

Weber, J. B., and Weed, S. B. 1974. Effects of soil on the biological activity of pesticides. Pesticides in soil and water, 223-256.

Wilson, L. G. 1980. Monitoring in the vadose zone: a review of technical elements and methods (Vol. 1). Environmental Monitoring Systems Laboratory, Office of Research and Development, US Environmental Protection Agency. 